\title{
Lighting the Colossus of Rhodes: A Beacon by Day and Night
}

\author{
By Robert B. Kebric ${ }^{*}$
}

This is one of several interrelated articles on the Colossus of Rhodes (Kebric 2019a, 2019b). Conclusions reached in those other articles, particularly one on the height of the Colossus, one of the Seven Wonders of the Ancient World, and the nature and size of any pedestal on which the giant statue stood, determined that it was at least 110 feet tall and stood on a three-tiered pedestal some fifty-feet high -- a combined height of 160 feet. These other ATINER studies also concluded that the Colossus, the largest statue in the Greek world and votive offering to Helios, God of the Sun and the island's patron deity, was located at the apex of the acropolis of Rhodes city among the island's other most sacred temples and monuments atop what is today known as Monte Smith. The latter, approaching about 300 feet in antiquity, would have elevated the Colossus some 460 feet above the sea below, and also made it an ideal "light tower" for vessels approaching and leaving Rhodes' five harbors. This study develops that idea to its logical conclusion, incorporating the latest information about such light towers on mountainous Greek islands (such as Rhodes). While there is no specific information about the Colossus as a lighthouse, there can be no doubt that Rhodes would have needed a light tower(s) on its heights from an early time. It is also logical that the Colossus would have been constructed with that purpose in mind from the start and assumed that function when built. Comparisons with the contemporary Lighthouse at Pharos, another of the Seven Wonders, and the modern Statue of Liberty, originally conceived as a lighthouse and close in size to the Colossus, are also included-- as is the reminder of the human inclination from earliest days to "light" tall structures that they build. The Eiffel tower is another more recent example. Suggestions as to how the Colossus could have functioned as a lighthouse, both by day and night, are also offered. Practical applications of expensive civic projects, especially long-drawn out ones, are also always an unavoidable consideration to city fathers of any period feeling community pressures: The Colossus was no different in that respect.

Keywords: Colossus of Rhodes, Helios, Seven Ancient Wonders, Ancient Rhodes, Chares of Lindos, Ancient "Lighthouses", Hellenistic Technology, Pharos at Alexandria, Statue of Liberty, Eiffel Tower.

\section{General Overview}

In a previous study on the Colossus of Rhodes (Kebric, 2019b), I concluded that the giant statue of the sun god, Helios, was situated atop the promontory now known as Monte Smith, above the modern city of Rhodes at the apex of the old city acropolis. It was also determined that the Colossus, completed around 280 B.C., was about 110 feet tall and was placed on a three-tiered base probably 50-

\footnotetext{
*Senior Professor of History (Retired), University of Louisville, USA.
} 
feet tall. When its combined 160-foot height is added to the elevation of Monte Smith, close to 300 -feet, the Colossus stood some 460 feet above the sea, making the tallest statue in the world also an ideal "lighthouse."

Such a lighthouse would have functioned in the same way smaller light towers once placed on Monte Smith previously had, only more efficientlyguiding arriving vessels to one of the five harbors at Rhodes City and signaling to communicate simple messages to other stations around the island. It was also appropriate that the Colossus, the embodiment of Helios, god of the sun, should continue serving into the night as a "star" in the capacity of a lighthouse.

While there is no information about the Colossus as a lighthouse, some hints may be gleaned about how it may have functioned as one by comparing it with details about the Pharos lighthouse, its contemporary "Wonder of the World" at the harbor entrance to Alexandria in Egypt. That structure would become the standard by which all subsequent lighthouses were judged ("pharos" became the Ancient Greek word for such facilities). An epigram about the Pharos by the poet, Posidippus (Gow \& Page 11; Astin \& Bastianini 115), whose poems place him in third century B.C. Alexandria, is very revealing because he had actually seen it in operation. His description immediately settles any question about whether or not the famous lighthouse, built during the reigns of Ptolemy I and Ptolemy II, had a great blazing flame at its top. Posidippus confirms that it did-- and adds that it could be seen by sailors all through the night to help guide their ships safely into the harbor at Alexandria.

Posidippus, from whose work one "reads the city [of Alexandria] through his poetry,"1 also confirms for us (unless he is speaking metaphorically) that the Pharos lighthouse, whatever its appearance and size at the time, was to be identified with Zeus the Savior, whose statue, most would agree, originally graced the top of the Pharos. However, it cannot be entirely ruled out that, as had become custom, such a manifestation of Zeus at the top of the Pharos could also have embodied Alexander, his "son," after whom the new city was named-- and also Helios, the sun, with which Zeus was identified in Egypt as Zeus-Ammon. The Pharos' flame was much like the sun, venerated as the patron deity of Rhodes. In fact, a much later sixth century A.D. mosaic representation of the statue atop the Pharos clearly represents it as Helios. Since Ptolemy I was also known as "Soter," or Savior, the allusion to Zeus the Savior would also have reflected favorably upon him. The one statue could represent many identities - just as Proteus, the "Old Man of the Sea," who had traditionally first lived on the island of Pharos, was polymorphic.

Interestingly, the Pharos did not make the list of Seven Wonders until long after the Colossus had fallen in an earthquake around 226 B.C-- but Posidippus' "eyewitness" epigram, confirms several issues that might otherwise distract us while trying to discover features which might also be associated with the Colossus as a lighthouse: There was, as previously noted, a blazing fire at the top of the Pharos Lighthouse-- but Posidippus also says that it continued to burn through the night, demonstrating there was no lack of "fuel," as some have argued, to supply

\footnotetext{
${ }^{1}$ Acosta-Hughes (2004).
} 
it. He further confirms that ships did, also contrary to the belief of many, continue to sail at night; and that, unlike at Alexandria, where the low profile of the breakwater necessitated building the Pharos straight up from sea at the harbor entrance, other Mediterranean seaports had positioned their "...look-out posts on a mountain, as in the islands...where ships take harbor." blazing flame at its summit to these other port "look-out posts," Posidippus confirms for us that such watch-towers, look-out places, or other distinguished heights "on a mountain, as in the islands," had similar flames and acted as the "lighthouses" of the day.

These individual details are important for any discussion about the Colossus because, as a lighthouse, it, too, would have had a fire(s) that burned all night; guided ships safely into port; and otherwise fulfilled the same maritime role Posidippus assigned to the look-out posts located high on mountain tops - in this case, at the mountainous island port of Rhodes, second only in importance to Alexandria.

Posidippus also wrote about the Colossus. In a more recently-discovered epigram (AB 68), he says that even though the Colossus was unrivalled in size, the citizens at Rhodes had pressed Chares, the sculptor from Lindos who had fashioned it, to make his colossal statue of Helios, "Twice its size." For a contemporary writer to have mentioned both the Colossus and the Pharos in his work is a welcome and remarkable happenstance-- but while Posidippus unequivocally states that the top of the Pharos blazed with a great flame, he says nothing about any fire associated with the Colossus. That does not, however, eliminate the possibility that it, too, had been designed as a giant light tower and was equipped with one or more beacons of fire. Posidippus was talking about two different monumental structures in two different epigrams at two different times, perhaps years apart - and in two different locations some 360 miles apart. He had no reason to mention a light(s) for the Colossus because it had nothing to do with what he was saying in his epigram. What he has done for us in respect to the Pharos, however, is to demonstrate that the "technology" did exist to produce a practical and sustainable "beacon" of light at the top for its operation. Consequently, it is a certainty that Chares also knew this because evidence from Philo of Byzantium (e.g. Belopoeica 51.10), who also lived at Alexandria in the third century B.C., ${ }^{3}$ demonstrates a long-time, close technological connection

\footnotetext{
${ }^{2}$ The translation runs:

(I)As a savior of the Greeks, this watchman of Pharos, O lord Proteus, was set up by Sostratus, son of Dexiphanes, from Cnidos.

For in Egypt there are no look-out posts on a mountain, as in the islands, but low lies the breakwater where ships take harbor.

Therefore this tower, in a straight and upright line, appears to cleave the sky from countless furlongs away during the day, but throughout the night quickly a sailor on the waves will see a great fire blazing from its summit.

And he may even run to the Bulls Horn, and not miss

Zeus the Savior, O Proteus, whoever sails this way.

(Translation by Dirk Obbink, University of Oxford)

${ }^{3}$ Marsden (1971, pp. 6-9) has established his date.
} 
between Alexandria and Rhodes. There were also scores of individuals passing continuously between the two cities who could have provided the same technical information.

Because Posidippus clearly demonstrates in his epigram ${ }^{4}$ about the Colossus that the citizenry of Rhodes had pressed Chares to make it even taller, an apparent impossibility, they most likely would not have been content to have it rivaled in any other way- especially by an impressive creation like the Pharos at Alexandria, Rhodes' "sister-harbor" and chief maritime rival. Twelve years of pressuring him must have taken its toll on Chares, so we can be certain that he did everything else not related to the Colossus' height to please them. That would have included whatever he knew to light it up as spectacularly as the Pharos. Just as its contemporary marvel burned brightly at Alexandria, the Colossus, standing high above the harbors at Rhodes, must always have been intended to perform the same function there. Consequently, we would argue that the Colossus was, like the Pharos, conceived from the start as a working "lighthouse," and that choice would have immediately impacted where it would have been placed: "on a mountain, as in the islands" - in this case, atop Rhodes' acropolis on Monte Smith, where the giant statue could be seen by anyone and everyone both day and night, on land and at sea.

People have always liked to light up at night the tall things that they build-doubly so at ancient Rhodes, one might suspect, for a colossal statue of Helios, who, after all, was the sun god. The Eiffel Tower, for example, the tallest structure in the world at the time, was fully illuminated on a scale never before seen for the 1889 Universal Exposition. It was for no other reason than the spectacle it provided - a declaration of French national pride. A contemporary image (Figure 1) of the Eiffel Tower shows it in its entire splendor- its spotlights focusing below on other buildings at the Exposition, while a higher beacon flashed round in red, white, and blue. The lighting technology for the Eiffel Tower, primitive by our standards, was as advanced as the day allowed. At the time of the Colossus, the only lighting available was that provided by managing some form of fire. Nonetheless, the much later Eiffel Tower is a useful example to demonstrate that no matter what the time, the cutting-edge "technology" of any age will be employed by those who are motivated to take the leap. We can be assured that Chares, too, would have stretched the boundaries of what had previously been possible to approach the "impossible" and make the Colossus a "wonder" in every way. The crowd, as Posidippus indicated, was really "into it," and Chares' statue also became a matter of "national" pride. The Rhodians probably took to heart Pindar's earlier observation in his Olympian Odes (7.53), dedicated in gold

\footnotetext{
${ }^{4}$ Translation of Posidippus' epigram (AB 68) on the Colossus:

The Rhodians wanted to make the enormous (?) Sun

Twice its size, but Chares of Lindus set it down that

No craftsman would make a statue even bigger than this one.

If that venerable Myron reached a limit

Of four cubits, Chares was the first with his art

To forge in bronze a figure [the size?] of the earth...

(Translation by Alexander Sens, Georgetown University)
} 
letters in the temple of Athena at Lindos, Chares' hometown, that the artists of Rhodes were so accomplished that their statues looked like they were actually walking down the avenues on which they stood.

\section{Figure 1. The Eiffel Tower}

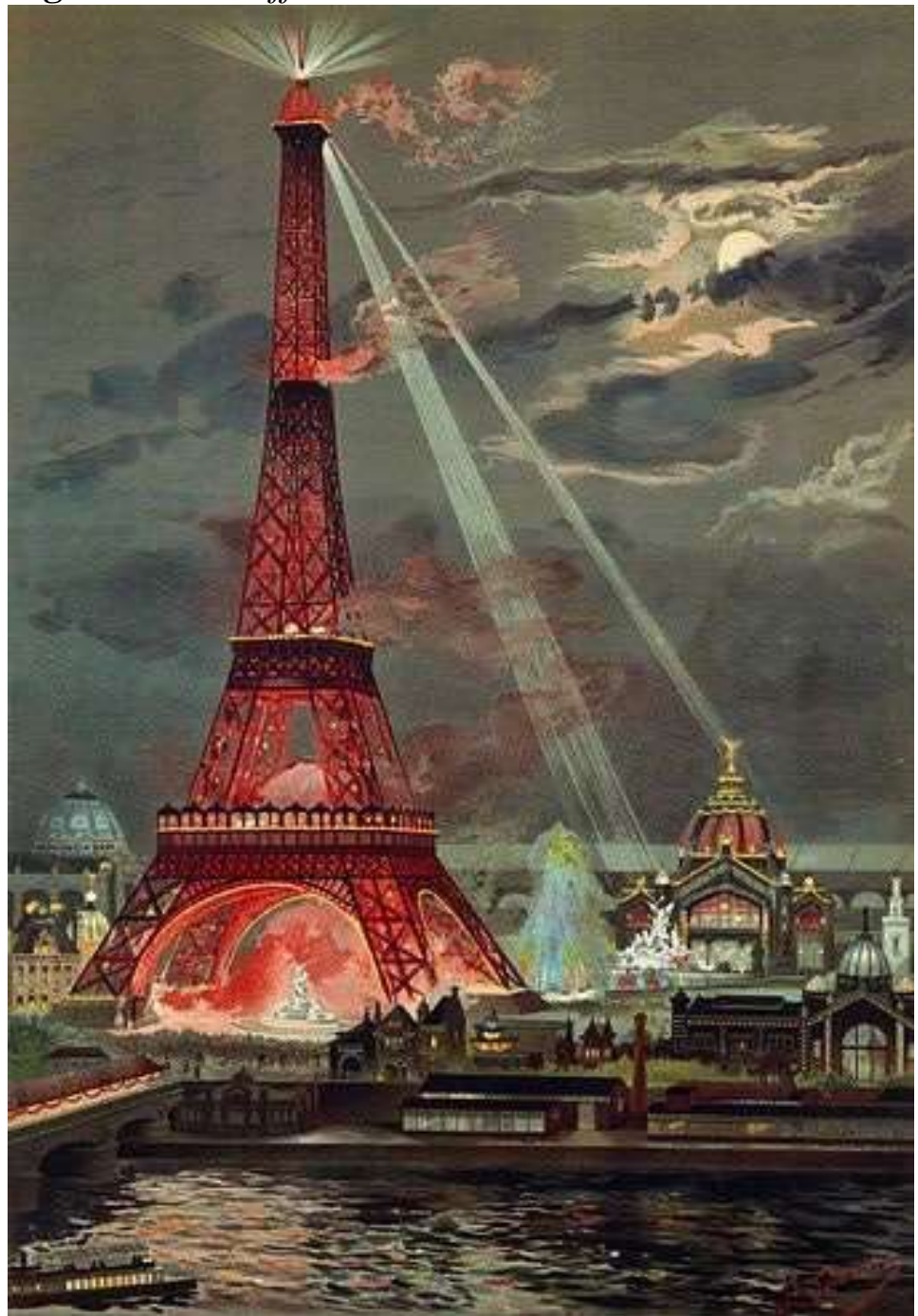

Note: A contemporary postcard image of the Eiffel Tower after dark during the 1889 Universal Exposition in Paris. Hundreds of gas lamps lit up the Tower, while a beacon at the pinnacle sent out, with the aid of Thomas Edison's creative genius, beams of red, white, and blue to the excitement of the crowds. The Exposition's Tricolorée set the stage for the later French-American bonds associated with the Statue of Liberty, whose interior structure was also designed by Gustave Eiffel. Searchlights on tracks illuminated exposition buildings below, a revolutionary moment in the history of lighting and the birth of the familiar "Sound and Light" spectacles at sites around the world we see today. In its time, it might be suggested, the Rhodians, too, attempted something similar with the Colossus - but within the bounds of their more primitive lighting skills and for more religious and practical purposes. 
Posidippus had written in his epigram that the Pharos had "a great fire blazing from its summit," giving Alexandria the same capability that the islands, in particular, had always had to guide ships to their harbors from "look-out posts" atop nearby mountains. Such "watch towers," going back to at least Homeric days, could not communicate any distance at night except by fire. They were also used to relay simple information. No one can forget, for example, Aeschylus' weary watchman in the Agamemnon, posted on the roof of the palace when he sees the blazing fire shining brightly in the dark night sky from a distant beacon that signaled the fall of Troy - a primitive system of signaling at the time, but one which would later be perfected for more precise communication by the historian Polybius (10.43-47).

By 400 B.C., the summits above each of Rhodes' four cities, all of which had harbors, would have similarly been used for signaling. Upon these same heights were located temples dedicated to Athena (and also Zeus at Rhodes City). It would be difficult to argue that it was not also normal practice to use such elevations, all at the top of each city's acropolis, to set fire beacons to communicate between themselves and to guide ships at sea. Such beacons would have become more sophisticated as Greek society progressed. At Rhodes City, they would have been located at the zenith of Monte Smith, its highest elevation, which we have already offered as the best location for the Colossus. Everything at that particular location fits nicely together: a large "fire tower" that had for years guided ships into Rhodes' ever-expanding harbors; the grandest temple on the island - and, now, combined with them at the summit was built a colossal votive offering to Helios, symbolizing Rhodes' independence, prosperity, and security. Once erected, there is no reason not to believe that the Colossus replaced whatever previous fire tower(s) there was atop Monte Smith, and assumed, like the Pharos at Alexandria, its primary function as a lighted beacon to guide sea traffic into Rhodes.

If all the Rhodians had wanted to do was build a colossal tribute to Helios, they could easily have done that on top of the tallest peak on Rhodes, Mt. Attavyros, almost 4,000 feet high, sacred to Zeus, and visible on a clear day from the heights of Crete some 100 miles away. Certainly, the ultimate choice for the Colossus' location would not have been capricious-- but one that would most effectively encompass all their needs. That would necessarily exclude a harbor-side site for a light-bearing Colossus-- including the now discarded but still persistent image of the giant statue bestriding the harbor entrance that still remains a favorite for non-specialists pondering its location. However, there were five harbors at Rhodes, and each of the three other major cities also had one - all war torn from Demetrius' siege, and, in the minds of their citizenries, at least, all deserving of the Colossus being placed on their acropolis. While a harbor at the island's capital seems to us a natural choice for the giant statue, that idea may be deceptive. Local patriotism and political divisiveness ran high at Rhodes, and the initial discussion of such a matter may not have been without "noise" before the final decision was made to erect it at the capital city, the bustling hub of the island's maritime business. There, it would not only serve as a glorification to Helios, who had protected the island during its siege 
by Demetrius, but also provide a shining beacon from atop Monte Smith for ships approaching any of its harbors - the single location from which such a beacon could be seen from across the channel in Caria and for miles around in every direction.

Compelling additional reasons to eliminate a harbor-level location for the Colossus are too glaring to ignore-- and two are definitive. Both Strabo (14.2.5) and Pliny, who actually saw or knew someone, who had, the ruins of the Colossus, state that they were lying on the ground. There was enough room, according to Pliny (34.18.41), for visitors to mill about and actually have contact with the statue's huge bronze remains. That necessarily means the Colossus, at least 110 feet tall (without its pedestal) had been located on an expanse of land that could still easily accommodate its giant ruined corpse. No jetty, mole, breakwater, or projection of land, natural or human made, at any of Rhodes' harbors could have accommodated such a massive amount of bronze-especially, as it appears, for centuries after its fall. The Colossus, itself, would also have to have been very accommodating by taking care not to fall into the water when it was toppled by the c. 226 B.C. earthquake.

The other definitive reason for not erecting the Colossus directly on the sea is that it was supported by an iron (and stone) interior framework. While bronze, malleable, durable, and attractive in appearance, is especially resilient to sea water and salt filled air-- iron is not. One has only to look at one's car during the winter to see what kind of damage the salt compound put on streets to dissolve snow can quickly do to an iron alloy (steel) frame and body. Traditionally, the Colossus was said to have taken twelve years to complete. With direct exposure to salt water and moist, salty air and winds, all parts of the Colossus would have been quickly "infected." The corrosion and deterioration of the metal would have started immediately while the statue was being built. Chares, an experienced sculptor and engineer, would have known that - and avoided it.

There are other negative reasons to dismiss any of Rhodes' five harbors as candidates for where the Colossus once stood. While its bronze exterior was well suited as a metal to survive outside for long periods, its skin was very thin, perhaps penny thin. Just to keep up its luster to reflect, as much as possible, the sunlight off its gigantic body and face, it would have to have been vigorously maintained on a daily basis - also, to prevent salt and other mineral deposits from building up and getting into the "cracks" and openings in the giant figure. Interior heat buildup had to be vented, and the Colossus did have to "breathe". That would mean there would always be large maintenances crews and their lodgings and equipment about the busy harbor(s), interfering with normal traffic.

As the tallest structure on the harbor, it also would have been (as are the Eiffel Tower and Statue of Liberty, in their respective environments) a giant lightening rod, potentially drawing powerful strikes to nearby buildings and ships and starting fires. The entire waterfront could be set ablaze. Over the twelve years of construction, a harbor side site also would have blocked or impeded both military and commercial ship traffic in what was one of the 
busiest ports in ancient Greece. That by itself would have made the project impossible there.

This was not a time of peace, and the recent siege by Demetrius was still in people's minds: It could happen again. The Colossus, a celebration to "victory" in the last war, could very well become the reason for subsequent defeat since its construction would have made the harbor(s) unable to respond quickly and decisively against any future enemy. Thucydides observation from a century earlier during the Peloponnesian War may be recalled (8.44.2), when the citizenry of the nearby city of Kamiros got so unnerved at just the sight of a Spartan fleet approaching their harbor unannounced, they immediately panicked and fled into the hills. What would the Rhodians have done had a valuable colossal statue been there to complicate matters?

Finally, a Colossus at the harbor holding a blazing torch or some other such "beacon light," routinely shown in early illustrations, would have been useless there. Its light would have been obscured almost immediately by the surrounding physical environment-- as can be seen today when one leaves the commercial harbor on a ship. It also could not be seen by most ships approaching the harbor until it was too late to be of any help. The beacon simply would have been too low to guide ships safety into its harbors-especially at night. Most of same reasons can just as easily be applied to eliminate a site for the Colossus close to the harbor behind the nearby walls-most popularly by the Palace of the Grand Master in the old city of Rhodes. That, of course, does not mean that other sizable statues described by Pliny, some colossal in size, could not have stood there and at other prominent places within the city.

These problems do not preclude a smaller colossal statue of Helios of some more resilient materials standing at one time near or at the major commercial or military harbor. In fact, it seems likely. Pliny had spoken of a number of such statues at Rhodes, but, even so, the closest he comes to a harbor side colossal figure in his discussion of colossi (34.18.39) is the much older 45-foot bronze statue of Apollo at Apollonia Pontica on the Black Sea (Bulgaria). Very recent archaeological work there, however, confirms that the statue was actually not at the harbor entrance but on an island with its temple across from the ancient city-- although the island may have once been connected to the mainland by a narrow breakwater of some sort, something like the one built in $1927 .{ }^{5}$ However, even had such a statue(s) of Helios earlier been standing near but not on a harbor at Rhodes, it would not have fared well during the siege of Demetrius-- or any potential future attack. More wisely, the Rhodians probably followed the classic example from the Athenians, who directed their energies first toward fortifying their harbor(s), while placing their most colossal figures out of harm's way, high on their Acropolis-- where, it was said, the sun shone so brightly off the helmet and spear of the Athena Promachos (nowhere near the height of a Colossus atop Monte Smith), it could be seen for miles out at sea.

\footnotetext{
${ }^{5}$ See, "Balkan Heritage Apollonia Pontica Excavation Project, Bulgaria, 2017,” online reference.
} 
At almost 300-feet above the city of Rhodes and the sea, there was no better place for the Rhodians to have initially set a signal fire than on Monte Smith, adjacent to the great temple of Athena and Zeus at the summit of their acropolis - and, subsequently, to replace that early beacon with the Colossus. The advantages of the heights of Monte Smith continued to be recognized well into modern times. Once a strategic place has been identified, it is seldom abandoned. Just over the past 200 years, Monte Smith (better known to locals as St. Stephens) was used by British Admiral Sydney Smith, whose name the mount now bears, as an observation post to monitor Napoleon's eastern Mediterranean naval movements; and, in World War II, the Italians established a fortress there with large gun emplacements. What this confirms is that the peak of Monte Smith has been fortified from the start, and that, in antiquity, it would have been from the ramparts of the Rhodian defenses located there that a fire tower would have been erected - simply because it was at this particular place where it could best "see" and be seen. Unfortunately, it was for this same reason that over the millennia, a continual rain of destruction has fallen down upon the tiny plot of land, obliterating in the process (along with frequent destructive earthquakes) most signs of anything that was ever there- including the Colossus.

Still, Rhodes was an island, and even at the top of Monte Smith it can be very windy, and salt is unavoidably in the air - but at such a higher elevation, the most pressing problems that a colossal figure would immediately have faced on the harbor (and in the city) were either eliminated or ameliorated. A similar situation can be found at San Francisco, where those who live on the shore of the bay suffer more from the effects of sea water and air than those who live higher up on Telegraph Hill. Interestingly, the same 275-foot hill shares another parallel with Monte Smith since it once served as a signal hill-in its case, as home to a semaphore that signaled the city about ship traffic entering the harbor in the nineteenth century and warned of potential dangers.

It is only logical that any previously existing light tower on the heights of Monte Smith would have later been replaced, or reconfigured, in favor of the much taller Colossus, which assumed that function in an appropriate architectural and practical fashion. Along with the Pharos, the Colossus was one of the two tallest structures of the time, rivalling even the older pyramids of Khufu and Khafre. On an island on the sea whose life blood was shipping, there is no reason to believe the Colossus would not have been used as a lighthouse. That being the case, what kind of light would have emanated from it; how would the receptacle or platform for such a light be placed on the Colossus-- whether on its "person" or nearby-- and what kind of technological enhancements were available at the time to increase the strength of its flame? Clearly, there had been much recent innovation in lighting "technology" that could also have been applied to the Colossus. 


\section{The Hellenistic Revolution in Technology}

At the time the Colossus was built, the Greek Mediterranean world was at a crossroads of change in most every respect. Sarton's pioneering work on Hellenistic Science and Culture was among the first to prepare us to understand more fully the impact the "Alexandrian Renaissance" had on the Greek world in the last three centuries B.C.-- and, also, on what followed during Roman times. Alexander's conquests had unavoidably resulted in a new diversity of Mediterranean cultures and opened the door to many novel concepts that became centered in the particularly unique, polymath atmosphere at Alexandria. New ideas, experimentations, and Ptolemaic funding seemed to spawn innovations almost out of the ether in technology, engineering, and weapons. We know of entire cities in the past that were abandoned to the elements, such as Roman Italica in Spain (near Seville), where the course of the Guadalquivir River (Roman Baetis) changed and left the major city where both Trajan and Hadrian had been born stranded and abandoned. Seldom do we have the opportunity like the one presented by Alexandria to observe an entire new city rising from the ground up-- especially one that would become the world's first metropolis.

People, material, wealth, and every other ingredient necessary to build a great urban center quickly collected at Alexandria, and it continued to expand. If the new citizens had not been fully aware before about the long tradition of Egyptian achievements, they were now - and that included monumental architecture (on a scale largely unknown in Greece), and colossal statues preceding the Colossus of Rhodes that could "talk," "sing," and gesture-- some, like the Colossi of Memnon, through natural anomalies; others by priestly manipulation. ${ }^{6}$

Many things taking place in the vibrant new cultural and technological atmosphere at Alexandria could also, ultimately, have been relevant to the design and building of the Colossus of Rhodes. There was demonstrated cooperation and sharing of knowledge between Rhodes and the Ptolemies in Egypt, who had assumed the role of protecting Rhodes. Ptolemy I, "Soter," most probably earned the epithet for his help in saving Rhodes from the attacks of Demetrius Poliorcetes in 305/4 B.C. What was happening at the Ptolemaic capital was attracting the greatest engineers, technicians, and artists of the day, and also affecting how Chares might have envisioned his own work on Rhodes, especially, the building of the Colossus. Philo of Byzantium, who penned the earliest surviving compilation of the "Seven Wonders," was, among other things, a contemporary weapons engineer who had been drawn to Alexandria at the time. He plainly demonstrated the cooperation between Alexandria and Rhodes when he stated that he freely shared information and associated with "many master craftsmen in Rhodes" (Belopoeica 51.10). The Pharos was also being constructed at the entrance to Alexandria' harbor-- and the Museum and Library were rapidly emerging as centers for all intellectual pursuits in the

${ }^{6} \mathrm{La}$ Grandeur (2012) has produced a fascinating essay on such matters. 
Hellenistic world. Clearly, much information was being shared between Egypt and Rhodes.

Already, Chares had as his own mentor the great sculptor, Lysippus, who had raised colossal statues. Whatever Lysippus had done, Chares built on his example- not only in the matter of height, but also in other respects that would have made his Colossus an even more unique creation. We usually think of height alone as being the reason for the Colossus' inclusion among the "Wonders of the World" - and, to be sure, it was the tallest statue ever built. However, just the physical presence of a gigantic statue may not have been enough to earn the Colossus its legendary status. The Pharos, for example, was also tall- but did not gain that same status until centuries later.

A much-overlooked passage from Pliny is valuable in establishing that the school of Lysippus, to which Chares belonged, had become known not only for colossal statues but also for innovative ways in which to make them move. What Pliny meant when he related that Lysippus' 60-foot statue of Zeus at Tarentum in Italy could be "moved by the hand" (34.18.40) is unclear-especially since Pliny had just noted that Lysippus had ensconced his large statue so firmly in place that the Romans had given up trying to transport it to Rome for display. Consequently, his statement cannot simply be referring to moving the statue from where it originally stood, but to its moving in place-- or moving some individual part(s)-- with apparent ease. There is no question about this since Pliny continues that Lysippus had added a column next to the Zeus to reinforce its stability, especially during storms, ensuring that it could not be dislodged from where it stood. The Romans could not do it, even though they had wished to take it to Rome.

Unfortunately, Pliny says nothing more about how the statue could be so easily "moved"-- but his tantalizing lack of description has led to speculation that some sort of device(s) inside the statue (or its base) worked by gears, counterweights, wheels, or even the kind of capstans used in siege craft that rendered the axles of the giant machines surprisingly easy to turn. Movement will always trump the traditional static pose of an artwork, especially a large one, but whether what Pliny describes was necessary to protect the statue or to move some part of it for dramatic or even religious reasons to enchant the crowds does not really matter. Lysippus had done something memorable-- and remarkable - and Chares would be criticized for not matching his own master's ingenuity. It seems a certainty that his Colossus did not disappoint.

While Lysippus had already demonstrated signs of innovations in what previously had been largely static sculpture, it was at Alexandria where Chares could turn to advance what he had learned from his mentor for ideas that went far beyond the bounds of his traditional craft. Ctesibius (c.270 B.C), ${ }^{7}$ first of the great Alexandrian engineers, lived and displayed his mechanical genius at the same time Chares was building the Colossus-- and if, as Posidippus indicates, public pressure at Rhodes was driving Chares to exceed the known

\footnotetext{
${ }^{7}$ See, Marsden (1971, pp. 6-9), for the date.
} 
bounds for sculpture of the day, Ctesibius certainly provided the Rhodian sculptor much about which to think.

Inventor, mathematician, engineer, weapons master, and more, there were few individuals who have ever influenced succeeding generations as much as Ctesibius did. The first of the great three mechanical and engineering geniuses at Alexandria was Ctesibius, his influence continuing on to Philo, his "successor," and then Hero, both of whom had no qualms about expressing their debt and admiration for Ctesibius. Ctesibius was the father of pneumatics, the use of compressed air to operate or move mechanical devices, and pioneer in its counterpart, hydraulics; and, while practically nothing remains of his writings, welcome descriptions of his revolutionary inventions were later preserved by Vitruvius in his De architectura (Books 9-10), which he dedicated to the Emperor Augustus. They include an early counter-weighted, adjustable mirror (presumably of polished bronze) for Ctesibius' father's barbershop at Alexandria, which could be lowered and raised as needed; the first water (and, also, pneumatic) organ and accurate water clocks; an innovative and highly-praised bronze-spring war catapult; a water screw; a water pump; and a variety of other fascinating objects.

Highlighting these latter imaginative creations were figures that could move, drink, and sing; mechanical blackbirds that could also sing; and other such amusements that were pleasing to the eye and ear that were, at the time, regarded more as "toys" for his Ptolemaic masters (and mistresses) than for any more serious application. This was partly because Ctesibius knew from where his support came, making sure to please Ptolemy's whims and desire to impress his guests; and partly because the technology (and materials) of the day restricted what was possible to do on a grander scale. It would not be the last time revolutionary concepts had to remain on the drawing board- or in the form of small models.

All of Ctesibius' inventions and ideas were early enough to influence Chares while he was building the Colossus. For his purposes, Ctesibius' advances were available to use in Chares' employment of reflective mirrors; precision use of bronze; accurate time keeping; devices that were operated through air pressure to open and close or raise and lower objects (already in use at Alexandria); music produced by water or compressed air organs; and statues that moved and vocalized, seemingly by their own will (something, perhaps, along the same lines of what Lysippus' had employed earlier in his colossus of Zeus).

It was inevitable that in such an innovative technological atmosphere-something like the early days of airplanes and cars in the twentieth century when new ideas were changing the products so rapidly it was difficult to keep up- the newest advances in technology and mechanics would also have found their way into the design and construction of the Colossus. They certainly did in respect to weapons development, where, in their own armories, the Rhodians shared the latest innovations with their counterparts at Alexandria.

Chares would not have hesitated to incorporate anything that enhanced his giant creation on Rhodes, as well as his own reputation, because such avant- 
garde additions would have made the Colossus a wonder in other respects beyond its amazing height. If it moved, "talked," acted as a horologe (its huge shadow serving as a giant gnomon dividing up the day), or incorporated mirrors to reflect more intensely the light from any fire beacon associated with the Colossus, so much the better. It would also be difficult to believe that Ctesibius' experimentation with mirrors stopped at his father's barber shop door. Why would anyone have bothered to make up such a story if Ctesibius had not been involved in such research? Hero's continued interest in the theory and construction of plane and curved mirrors in his Catoptrica would indicate that it had not (the same can also be said about the temple doors that opened and closed through pneumatics, an innovation usually ascribed to Hero). Music provided by small organs may also have been played at appropriate times (see Figure 2).

Figure 2. A Restored Pneumatic Organ Discovered Among the Ruins of the Roman City of Aquincum, Today in Greater Budapest.

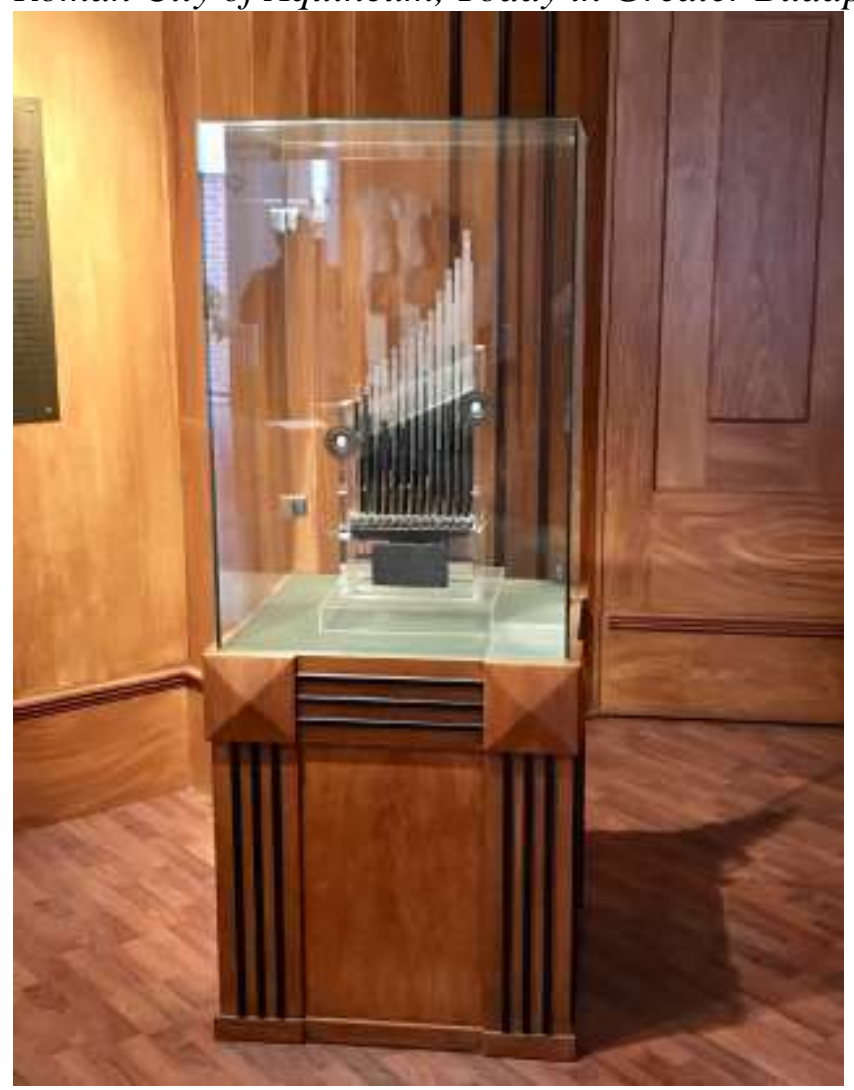

Note: It is our finest example of what Ctesibius' organ must have looked like in the third century B.C. A modern recreation of the original is actually playable.

\section{The Colossus: A Product of its Time}

This discussion began with the proposal that one of the reasons the Colossus of Rhodes would have been erected atop Monte Smith, the peak of the Rhodes City's acropolis, was that it was the only location where the giant statue could 
have been placed to serve in any effective capacity as a "lighthouse." Monte Smith was the highest local site from which to guide safely what would have been a constant flow of ocean traffic to-- or by, if ships were going elsewhere-- the harbors at Rhodes.

Posidippus' description of the Pharos at Alexandria leaves no doubt about its blazing flame-- but, as already noted, neither he, nor anyone else, says anything about a similar flame for the Colossus that would have taken over duties formerly performed by a light tower atop Monte Smith. There can be no doubt that there previously was a light beacon at the apex of the Rhodian acropolis, probably set on one of the city wall towers, because Posidippus indicates placing such towers on mountain tops on Greek islands was common practice. Since we are proposing that the Colossus of Rhodes was also located at the top of Monte Smith, it only makes sense that the much taller Colossus, when built, would have replaced any previous light tower as the primary pharos for Rhodes. There would be no need for two "lighthouses" at the same place.

It may be safe to say that the Colossus' service in the capacity of a lighthouse would have attracted even more attention to it and was an additional reason why it was included among the original "Seven Wonders" of the World- even overshadowing the Pharos at Alexandria, which was not in the original lists of Wonders, seemingly a glaring oversight to us. The reason may be due in part to what the Pharos looked like at the time the Colossus was finished. It was probably not as spectacular as it would be in later centuries - perhaps only a larger version of a light tower that had previously been at Pharos. By way of comparison, one typically thinks of the original Temple at Jerusalem in terms of what the impressive reconstructions of the later Second Temple must have looked like when destroyed by the Romans in 70 A.D. At the time of Solomon, however, the Hebrews were not architecturally advanced enough to have built anything comparable to the later images. Philo of Byzantium, who resided at Alexandria while both the Colossus and the Pharos stood, was not moved enough by what he saw to include the latter with the Colossus in his De septem orbis spectaculis, the earliest list of "Wonders" we possess. Perhaps, it was because he saw it every day, and while it certainly must have been an eye-catching structure for no other reason than it was at the entrance to Alexandria's harbor, Philo may have viewed it more as a functional building that was much too common and workman-like to be included. Unattractive smoke and soot from its large fire must also have bellowed over the new city to the dismay of residents when the winds were right. Its impressive later exterior also may not have been there at the time.

Philo liked the grand appearance of the older walls at Babylon better, which he chose to include over the Pharos in his list- perhaps because Alexander's presence and subsequent death in Babylon added to the contemporary mystery of the place. Unlike Alexander's connection in some way to all the other "Wonders" during his lifetime, the king had nothing to do with the Pharos-- other than ordering it built before his death.

There is also the lingering "tradition" that because the flame from the Alexandrian Pharos needed to be seen by ships from much further distances, it was enhanced in some way by a mirror(s) of polished bronze - the idea being that the 
flame could be reflected off such a "mirror" and even direct the light in a more specific direction(s). There is no contemporary reference to confirm the use of such mirrors-- not even Posidippus-- and what references we do have about mirrors at the Pharos are from a much later date: Pliny, for example, says (36.18.83) that in his time, the uninterrupted fire from the Pharos' beacon could be seen from so great a distance that it could be mistaken for a star. That certainly sounds like an "enhanced" version of a simple fire. As is often the case, the ancient sources are silent about the things we most want to know.

Nonetheless, the fact that the Pharos Lighthouse and Ctesibius were in Alexandria at the same time would certainly make it improbable that Ptolemy would not have asked his in-house genius to "play around" with how the light from the Pharos could be enhanced. Ctesibius and the other "geniuses" assembled at Alexandria certainly would not have been idle in advancing the technology of reflected light and how best to employ it. The Ptolemies would have seen to that since their continued power largely rested on sea traffic. Ctesibius' talents could realistically have been employed to enhance the flame from the Pharos just by use of a larger version of the mirror(s) of the reputed "barber shop" variety he was credited with inventing. That it was adjustable, as was the one in the barbershop story, and moved up and down through a system of counter-weights to vary the Pharos' light, is also more than likely.

If some system of mirrors actually were employed at the Pharos, it would only have been an extension of the use of mirrors already going back centuries in Ancient Egypt. Workmen in the tombs of Egypt had long before perfected the art of "throwing light" from one place to another by using mirrors to illuminate the inside of tombs, providing light for those excavating them, and, subsequently, for those painting the tombs' interiors. Torches could never have been used because of the smoke they produced-- and they used up all the oxygen in the tomb. This system of mirrors is still in use today when tourists are shown into the otherwise dark tombs of ancient Egyptians where electricity has not yet reached. A direct beam of intense sunlight from an opening purposely cut in the roof of a darkened ancient temple or tomb can also be reflected off something as simple as one's light-colored clothing- especially white shirts or blouses.

Ctesibius would have known about this routine method of providing light from the sun by mirror relays, as would other engineers at Alexandria, and he could very well have advanced the basic concept and employed it in a lighthouse. Herodotus relates that a shield signal was flashed for seemingly traitorous intent by pro-Persian Greeks from the hills above Marathon directly following the battle in 490 B.C. --from what would necessarily have to have been an especially shined bronze surface. The episode has attracted much mixed discussion, but our only interest here is that Herodotus knew about such shield signals- which means that they did exist, and they did work.

We have an even earlier Greek example of how mirrors could have been employed in difficult engineering projects because they provide the best explanation for how the tunnel of Eupalinus on the island of Samos was excavated during the reign of Polycrates in the sixth century B.C. Even Herodotus, who did not like tyrants, included the 3,300-foot tunnel cut through the middle of a 900- 
foot high hill as one of Polycrates' greatest achievements. What was especially remarkable is that workmen started simultaneously at the base on either side of the hill- and met in its middle. A short distance in from the south entrance of this tunnel are the remains of a vertical light shaft Eupalinus had cut to project a blinding ray of sunlight into his otherwise dark excavations below. It was obviously there for an important reason, and it is positioned immediately before the actual "doorway" to the tunnel proper. The most reasonable explanation is that a blinding beam of light-- in otherwise complete darkness-- hit a large mirror on a fixed base with a fixed angle that was positioned directly below it, and that mirror subsequently reflected the same light to a second in a relay of mirrors that were placed further into the tunnel as the work progressed. Theoretically, at least, all the workmen had to do was maintain the original direction by following the point of light from the mirrors. The original light source probably could not have sustained such a point of light over a long distance (in this case half the distance through the hill), so one might surmise that, as in the case of the Ancient Egyptian tomb workers, a system of relay mirrors was set up to keep the light strongly focused in the correct direction(s). The basic premise, at least, was successfully tested in the tunnel in the 1970s.

Because Eupalinus' tunnel was started on both sides of the hill at the same time, the procedure for excavating the second tunnel (now inaccessible) would have likewise been followed-- and, remarkably, with the additional use of a water level (the main reason for the tunnel was to transport water to the city) to keep the tunnels at the same height as the workmen progressed, they successfully met in the middle of the hill. Until recently, that would have been difficult for modern technology to match. Pythagoras was on the island at about the same time, but the idea that he had provided the engineer(s) with a version of the "Pythagorean theorem" to help guide the course of the tunnels has been dispelled by ground surveys around the hill, whose terrain is much too uneven for any of kind of such scheme to work. There are no other physical signs in the roof of the tunnel or elsewhere to suggest the employment of known techniques for building similar underground works, such as drainage tunnels in Egypt. On Samos today, one can still see bronze mirrors from the period displayed in the main museum.

Ctesibius, already familiar with the reflective qualities of mirrors, was available to put his own genius to work over two centuries later at the Pharos of Alexandria. For someone as shrewd as Ptolemy not to have employed him in improving the quality of light projected from the new lighthouse would defy logic. It was, after all, the single most important beacon directing the many ships coming to Alexandria with everything needed to make his new capital the greatest city in the world.

The Pharos lighthouse at Alexandria was made of stone, and at its top was a great flame that has all appearances of being enhanced by a large bronze mirror(s). Conceiving of a huge, sun-reflective, polished bronze statue of Helios at Rhodes that also acted in some manner as a lighthouse should therefore not surprise us. People have always noticed whatever there is in their environment that reflects their countenances. The most primitive people could see their reflection in pools of water. Bronze mirrors go back to the time when someone also realized they could 
see their features on a bronze surface if it were polished up enough. Greek pottery is ubiquitous with representations of prosperous women at their toilet holding mirrors. Mirror factories turned out decorative mirrors routinely for local and trade consumption. A city as large as Rhodes probably had several. Alexandria, likewise - and hundreds more were all over the Mediterranean. It was already a long-established and profitable industry.

Colossal bronze statues, some already more than half the size of the Colossus, had been "in production" for more than two centuries before Chares built his giant at Rhodes-- so an industry, probably mostly slave-based, to maintain, clean, and polish such statues, had already developed. Polishing something the size of the Colossus of Rhodes was probably like painting a bridge today: the job starts over again as soon as the last brush of paint is applied. And the Colossus must have been highly polished (like the outer skin of the Egyptian pyramids) to enhance its reflective character. The resultant effect of such labor, shining in the intense Rhodian sunlight, must have been awe-inspiring-- moving any individual at ancient Rhodes to feel pride about it. Also, for anyone thinking about advancing on the island again with bellicose intentions in the unsettled period following the death of Alexander, the gleam from the sun off the statue- certainly even more impressive than the storied reflection off the helmet and spear of the Athena Promachos at Athens, must have been an intimidating reminder that the island was under Helios' protection.

Today, one can purchase polished sheets of bronze for their homes or businesses - and they, like the bronze skin of the Colossus, require attention to keep their sheen. One need only look at bronze jewelry for purchase on-line to see the bright luster that can be produced. Keeping a 110-foot bronze statue gleaming seems daunting - even an impossibility-- considering the intensive labor required. But so, too, does the building of the Great Pyramid, the earliest of the "Seven Wonders," over two millennia earlier - and it also had a polished exterior to reflect the glaring Egyptian sun. When massive work forces are available to complete massive projects, they get finished, in amazing times. This is especially true when there is a religious motivation, as there was for the Colossus, as well as a tremendous amount of community pride. At the minimum, the exterior of surviving bronze statues today, a number even rescued from the sea, reflect pleasingly off museum lights; at maximum, statues aggressively polished to a shine in antiquity by an expert labor force must have looked absolutely brilliant in the light.

The Colossus was a votive offering to the sun, a religious object, not just another statue-- and Helios did not want to be disappointed by his image. Keeping it shining would mean there would have to have been a large force of labor constantly on call. Such an on-going procedure would also have to have been carried out without invasively interfering with the daily appearance of the Colossus and its aesthetic appeal to those at home and from abroad who looked at it as a marvel and symbol of Rhodian pride and power.

The technological advancements of the third century B.C., both in war and peace, as well as the innovations for light towers, or "lighthouses," in particular, incorporated into the construction of the greatest one at the Pharos in Alexandria, 
would also have accordingly advanced the technology of such towers everywhere else- especially for the busy harbors at Rhodes, where the Colossus was being built. It can therefore be proposed with some confidence that the functions previously performed by a separate lighted watch tower(s) atop Monte Smith would now have been transferred in some more effective capacity to the Colossus, and that the latter, because of its additional height, acted not only as a super light tower but also as an illuminated day and night spectacle in the name of Helios, the sun god and patron of the island.

Any fire associated with the Colossus as a light tower, however, would not need to have blazed as brilliantly as that of the Pharos because Rhodes was located directly across the channel from Caria (only nine miles across from the modern capital city) and there were other islands nearby, so its light could easily be seen by approaching ships. There were also lights from the heights of the Rhodian towns of Kamiros and Ialysos on the same side of the island by which ships could guide themselves at night. A simple but effective fire, then, may have been all that was needed, and it still would have pierced the darkness from miles away. Nonetheless, reflecting that same light using a polished bronze mirror(s) would have tremendously enhanced the light and its all-around effect, something that would have been desirable if for no other reason than spectacle. That a torch or bowl-like container would have been "built into" or attached to the colossal statue or a raised arm, as sometimes shown in illustrations, is probably unrealistic since the continual heat generated by such a blazing fire so close to the bronze skin of the Colossus would have melted its metal- or at least progressively damaged it. Soot from the smoke would also be detrimental to the statue.

Before the Colossus was even built, the system of handling fire at watch towers had undoubtedly improved to the point that, instead of climbing to the top of the tower to ignite a fire, which could be dangerous in itself, the Greeks had advanced the technology to the point that the fire could be kindled at ground level and then raised to the top of a tower, circular or squared, masonry and/or metal, by a simple system of internal pulleys or counterweights. In such manner, fireresistant "bowls," or platforms of fire, wood or oil fueled, could be raised as simply as Pliny indicates Lysippus had made his statue of Zeus at Tarentum "move by the hand." Such a system could just as easily have been transferred to the Colossus and immediately have made it the rival of the Pharos at Alexandria. It was, after all, already perched on an almost 300-foot cliff and with its pedestal was another 160 feet high. The top of Colossus' 50-foot stone pedestal could, by itself, have acted as the station for the fire(s) in cauldron(s)-- or a large tripod(s), placed at the corners directly below the statue. Such corner decorations were not unusual on large platforms - in this case they would have been containers for fire. That would have saved the Colossus's bronze skin from damage. Perhaps even better, a separate pillar, or pillars, of fire could have been stationed, much like Lysippus had constructed a separate column a short distance from his colossal Zeus at Tarentum to help stabilize it, near the Colossus, so that there was no chance of affecting it negatively. The Colossus certainly would also have needed such an external support(s), possibly even built into its design, to provide an integral and aesthetic appearance. Such a support could have been made of something other 
than bronze that could hold a long-burning fire without damage to the apparatus that held it.

Whatever the light source designed for the Colossus, it, too, could have been intensified by the employment of bronze sheet mirrors, which most likely once enhanced the flame of the Pharos. Chares, a master of his craft, would have worked out a way. His fellow citizens, especially the ones clamoring for him to do more, would have been pleased.

Any idea that the Colossus held some type of lighted torch in his raised hand or had a "bowl" of fire in front of or above his face, however, would appear to be pure fantasy. The technology of the day simply did not exist to supply a practical torch or fire on the Colossus at such a height-- and, even if it could be done, the heat from it would melt the statue's thin bronze skin. Managing the natural heat and the daily expansion and contraction it caused (especially within the Colossus), was an engineering feat by itself. There must have been many "air vents" in the Colossus' outer skin to avoid an extreme buildup of heat and to allow workers the conditions to work within its interior. (Such heat and expansion and contraction problems also affected the Statue of Liberty - as did the difficulty in sustaining her raised torch arm, which can sway as much as six inches in a strong wind.)

None of this, however, means that there was not a beacon of fire associated with the Colossus, and that the giant figure was not designed from the start to act as a "lighthouse." As already seen, illuminating tall structures has always fascinated beholders. The Eiffel Tower, while not a lighthouse, was the tallest building in the world, and it would be unrealistic to believe that it could ever have passed without some plans to light it up. The Statue of Liberty, the tallest concrete and metal structure ever built to its day, was conceived (and used) from the start as a lighthouse (although not a very effective one, it appears) to help guide ships into New York Harbor. President Grant may never have okayed the plan to place it where it is, if he had not thought it was going to serve in that capacity. Fortunately, Liberty remains fully illuminated today for other reasons - but no one could ever imagine it sitting in darkness every night. Similarly, would anyone suggest that the Colossus, along with the Pharos the tallest structure built since the pyramids over 2,200 years earlier, would not also have been "illuminated" at night-- as far as the technology of the day allowed. Rhodes was both the gateway to the Aegean from one direction and the gateway to Alexandria, the greatest city in the world, in the other. Perhaps, it was not just its size that won the Colossus of Rhodes its place on the list of the wonders of the world.

\section{Concluding Observations}

A flame tower could easily have been conceived and erected to stand near or be attached to the Colossus. A double-iron-framed structure of basic design, hardly visible from a distance, with pulleys that could raise and lower fire platforms or pods in tandem, one replacing the other as the fuel expired to produce continuous light, would not have disturbed the statue's thin bronze skin. Rhodes is full of pine trees to use as fuel (and also probably exported to 
Alexandria, where wood was scarce), but the natural commodity could be used quickly if fires were maintained throughout the day and night. The need for sustainable fuel was probably what early on sparked the idea that a lower intensity fire could be used if highly polished bronze mirrors were arranged to reflect additional light. Projecting light with mirrors was already an established fact. If the same simple procedure could also be used at night with fires providing the light instead of the sun, there may also have been mirrors situated below to reflect light off the highly buffed bronze body of the Colossus and illuminate it. Like lighting the Eiffel Tower in its time, someone as clever as Chares and the collection of other geniuses, who, like Ctesibius, were working with light refraction at Alexandria, certainly could have come up with some equivalent lighting system. There is, of course, no way of demonstrating this on the same scale, but, theoretically, the material and know how was available to enhance any light source emanating from the Colossus and also illuminate the surrounding area below it. Lights always burned continuously at religious shrines in ancient Greece- and the Colossus was, after all, a gigantic votive offering.

The ideas presented here are just that - but it is probable that some of them could have had a practical application for the Colossus. There would be no reason not to provide an illumination system for the Colossus if technically possible, and the technology to do so was advanced enough to make it so. Building the Colossus as a "futuristic" light tower would also undoubtedly have been a "selling" point to any reticent city fathers who ultimately valued profit over safety concerns. They were on an island, and they could not exist or continue to grow without expanding commerce. Most people have no idea that the Statue of Liberty was "pitched" by supporters as a lighthouse in order to give it the needed commercial attraction for financial support.

Finally, the copious supply of daily sunshine hitting the giant body of the Colossus left below on the ground a distinct shadow that could have acted as a community sun dial. It was common practice to use the shadows of huge physical objects, even mountains, as a way of keeping time. Augustus would later use a 100-foot obelisk he had brought from Egypt and placed near the Ara Pacis on the Via Flaminia to indicate the time of day. The Solarium Augusti functioned as a solar marker, with a gnomon whose shadow marked the time of day on the calibrated pavement below. It was the first solar monument at Rome, and on Augustus' birthday, September 23, its shadow fell directly on the center of the Ara Pacis. Interestingly, Eratosthenes, the man who produced the first realistic measurement of the earth's circumstance, was heavily involved at Alexandria with gnomons measuring the sun's shadow during the same period Ctesibius was active there-- and while the Colossus was standing.

Blazing light tower fires, bronze mirrors, precision time calculation, and statues with moving parts that "spoke," sang, and played music - they, as well as other innovations just as fantastic to onlookers, were all part of the cultural fabric of the day. The ability to incorporate any or all of them in the Colossus of Rhodes while it was being built was unquestionably there. And the only location on Rhodes where most, if not all, of these things, along with the 
Colossus' incredible size, could be most effectively accommodated was high above the city on its acropolis at the apex of Monte Smith.

\section{References}

Acosta-Hughes B (2004) 'Alexandrian Posidippus: On Rereading the GP Epigrams in Light of P.Mil.Vogl. VIII 309' in Labored in Papyrus Leaves: Perspectives on an Epigram Collection Attributed to Posidippus (P.Mil.Vogl. VIII 309). Hellenic Studies Series 2. Washington D.C.: Center for Hellenic Studies. Online version.

La Grandeur K (2012) 'Robots, Moving Statues, and Automata in Ancient Tales and History' in Carol Colatrella (ed) Critical Insights: Technology and Humanity, Amenia, NY, USA: Salem Press.

Kebric R.B (2019a) 'The Colossus of Rhodes: Its Height and Pedestal' Athens Journal of Humanities and Arts (forthcoming)

Kebric R.B (2019b) 'The Colossus of Rhodes: Some Observations about Its Location' Athens Journal of History (forthcoming)

Marsden E.W (1971) Greek and Roman Artillery Technical Treatises, Oxford: Oxford University Press. 
